\title{
Serum cholesterol-lowering efficacy of stanol ester incorporated in gelatin capsules
}

\author{
Hanna Lagström', Hans Helenius ${ }^{2}$ and Pia Salo ${ }^{3}$ \\ ${ }^{\prime}$ Research Centre of Applied and Preventive Cardiovascular Medicine; ${ }^{2}$ Department of Biostatistics, University of \\ Turku, Turku; ${ }^{3}$ Raisio Life Sciences Ltd, Raisio, Finland
}

\section{Abstract}

Background: The cholesterol-lowering properties of plant sterols have been known since the 1950s. In most clinical studies the efficacy of plant stanol ester has been studied when incorporated into mayonnaise, regular or low-fat spreads or yoghurt.

Objective: The purpose of this study was to confirm the cholesterol-lowering efficacy of plant stanol ester when incorporated in capsules as part of a normal everyday diet.

Design: The study had a randomized double-blind parallel design with an intervention period of 3 weeks. Forty-two subjects were randomized to receive either the active capsule ( $2 \mathrm{~g}$ of stanol) or the placebo capsule. Results: Stanol ester capsules effectively decreased the low-density lipoprotein (LDL)-cholesterol level by $8.5 \%$ [ $95 \%$ confidence interval (CI) 4.1 to $13.0 \%, p<0.001$ vs baseline, $p<0.05$ vs placebo]. Total cholesterol concentration was reduced by $4.6 \%(95 \%$ CI 1.3 to $8.0 \%, p<0.01)$ and the apolipoprotein $\mathrm{B}$ level by $6.5 \%$ $(95 \%$ CI 2.0 to $11.0 \%, p<0.01)$ versus baseline. The LDL/HDL ratio was reduced by $10.6 \%(95 \%$ CI 5.2 to $16.0 \%, p<0.001)$ versus baseline.

Conclusions: Plant stanol ester reduces LDL-cholesterol effectively, even when provided in a fat-free matrix such as capsules.

Keywords: adult; cholesterol lowering; gelatin capsule; intervention; serum cholesterol; stanol ester

Received: 29 Jun. 2006; Revised: 4 Jul. 2006; Accepted: 21 Aug. 2006

\section{Introduction}

$\mathrm{T}$ he cholesterol-lowering properties of plant sterols have been known since the 1950s (1).

Plant sterols decrease the absorption of both biliary and dietary cholesterol from the small intestine (2). The saturated form of plant sterols, plant stanols, decreases the serum levels of both cholesterol and plant sterols and stanols are not absorbed to any significant degree (3).

Fat-soluble plant stanol esters were developed to be used as an ingredient in different food products to achieve significant reduction in serum total cholesterol and low-density lipoprotein (LDL)-cholesterol levels. Plant stanols are currently recommended for cholesterol lowering by several authoritative bodies, e.g. the US National Cholesterol Education Program recommends plant stanols or plant sterols as part of therapeutic lifestyle changes when normal dietary measures are not effective enough (4). According to a meta-analysis of clinical trials, the optimum daily intake of plant stanols is $2-3 \mathrm{~g}$ as plant stanol ester (5). So far, the cholesterol-lowering efficacy of plant stanol ester alone has been confirmed in more than 40 clinical studies. In most of the clinical studies the efficacy of plant stanol ester has been studied when incorporated into mayonnaise, regular or low-fat spreads or yoghurt (6-8). Previous studies have shown that incorporation of unesterified stanols in capsules does not have a significant cholesterol-lowering effect (9).

The purpose of this study was to evaluate whether esterification of plant stanol restores the cholesterol-lowering potential of plant stanol when administered as capsules.

\section{Methods}

\section{Subjects}

In total, 45 subjects with normal serum cholesterol to mild hypercholesterolaemia (serum total 
cholesterol between 4.5 and $7 \mathrm{mmol}^{-1}$, and total triglycerides below $3.0 \mathrm{mmol}^{-1}$ ) were recruited to the study at Nokia Ltd occupational health-care centre in the city of Salo (south-west Finland). Other inclusion criteria were age 35-55 years, normal liver, kidney and thyroid function, no lipid-lowering medication and no history of unstable coronary artery disease (myocardial infarction, coronary artery bypass graft or percutaneous transluminal coronary angioplasty within the previous 6 months, diabetes, temporal ischaemic attack and malignant diseases). Subjects with alcohol overconsumption ( $>2$ portions per day or more than 16 portions per week) and pregnancy were excluded. Subjects using plant stanol or plant sterolcontaining products were excluded, although those who discontinued the consumption of these products a minimum of 3 weeks before the beginning of the study could be included. The inclusion criteria were checked during the screening visit before randomization. Of the recruited subjects 42 (20 men and 22 women) subjects were eligible to participate in the study.

The subjects gave written consent for the study and before initiation of the study. The protocol, the subject information leaflet and the informed consent form were approved by the ethics committee of the Health Care District of South-west Finland.

\section{Study design}

The study was carried out from the beginning of February to the end of March 2005, applying a randomized, double-blind, parallel design with an intervention period of 3 weeks. Randomization was done stratified by serum cholesterol levels and gender, i.e. men with serum total cholesterol $\leq 5.7$ and $>5.7 \mathrm{mmol}^{-1}$, and women with serum total cholesterol $\leq 5.7$ and $>5.7 \mathrm{mmol}^{-1}$ separately to ensure the comparability of the groups. Total cholesterol used in randomization was measured from the first blood sampling of the study at the screening visit. After the screening phase all subjects were be randomized into one of two groups. One of the groups received placebo capsules and the other group used similar capsules containing plant stanol ester ( $2 \mathrm{~g}$ of plant stanol; Raisio plc, Raisio, Finland).

Routine laboratory measurements were taken to ensure normal health status at the first and last visit of the study. In addition, health history, current medication, alcohol and tobacco consumption were explored through interview by a structured questionnaire on the first visit of the study. Fasting blood samples were taken at the beginning of the pretrial period (week -1 ), at the beginning of the experimental period (week 0), and twice at the end of study period ( 3 weeks; variation between blood samples 2-5 days). Body weight was recorded at the beginning (week -1) and end of the study (3 weeks). Possible adverse effects and symptoms were recorded in a diary during the study.

\section{Test products and diet}

Experimental products were capsules containing $830 \mathrm{mg}$ of plant stanol ester per capsule, corresponding to $490 \mathrm{mg}$ of stanol in one capsule. Placebo capsules contained $830 \mathrm{mg}$ of rapeseed oil. The stanol was derived from soya oil sterols and the fatty acid ester from rapeseed oil fatty acids.

The targeted daily intake of plant stanols from the stanol ester capsules was $2.0 \mathrm{~g}$. Therefore, the targeted daily number of capsules was four. The subjects were advised to take capsules with a meal: either four capsules with one meal (preferably breakfast) or two capsules with two different meals.

Diet was monitored by food frequency questionnaires at the start and end of the study to follow possible changes in the consumption of foodstuffs that influence serum cholesterol levels. A food frequency list was checked immediately in the presence of the subjects by study personnel for incomplete filling or other deviations. In addition, subjects recorded the daily number of capsules and time of consumption, as well as possible side-effects, in a daily diary, and they were asked not to change their habitual diet or physical activity habits during the intervention.

\section{Laboratory measurements}

All blood samples were collected after a $12 \mathrm{~h}$ overnight fast. Blood samples were not taken on Mondays to minimize the effect of dietary changes at the weekends. Blood count, serum $\gamma$-glutamyltransferase (s-GGT) and serum alanine aminotransferase (s-ALT) were measured at the beginning and end of the study to ensure normal health status of the subjects. Serum high-density lipoprotein (HDL)-cholesterol, total cholesterol and total triglycerides were analysed by enzymic photometric methods using commercial kits (Thermo Clinical, Finland). LDL-cholesterol estimates were calculated by Friedewald's equation. Apolipoprotein A 
and B were analysed immunonephelometrically (DadeBehring BNA, Marburg, Germany).

\section{Statistical analysis}

The power calculations were done for LDL-cholesterol as the primary outcome variable. It was assumed that the treatment effect would be at least a $10 \%$ decrease in the mean value of $\operatorname{LDL}(5,9)$. It was also assumed that in each of the experimental groups the baseline values for mean and standard deviation of LDL would be about 4.5 and 0.7 , respectively $(5,9)$. The values of $\mathrm{LDL}$ were the average of two recordings. If the standard deviations of the two initial recordings were 0.7 , the standard deviation of their average is 0.49 . The treatment effect of a 0.5 unit decrease in the mean value of LDL would correspond to a decrease of $11 \%$. There was expected to be clear correlation within the subjects between the repeated measurements at the baseline and at the end of follow-up. This correlation was assumed to be 0.60 . Comparison of the treatments was carried out by testing the difference in the mean LDL changes during the follow-up, using two-sided, two-sample $t$-tests. The power was chosen to be $85 \%$ in the calculations. The power calculations showed that if there was a 0.5 unit difference in the mean value of treatment group compared with the placebo group it would be significant at the level of 0.017 , if the number of subjects in each group was 15 . The significance level corresponds to $\alpha=0.05$ after Bonferroni correction due to three comparisons. Because of possible dropouts, the number of subjects were fixed to be at least 20 in both experimental groups.

The statistical significance of differences between the treatment groups in the baseline measurements and in the baseline characteristics was evaluated using the chi-squared test for categorical variables and a two-sample $t$-test for continuous variables. Wilcoxon's rank sum test was used for comparisons between treatment groups in the difference of the number of days between visits. The treatment effect in each lipid and blood variable was analysed by studying the change in values recorded before and after the treatment period. To eliminate the random fluctuation in one laboratory recording for each subject the average value of visit 1 and visit 2 was taken to represent the value before the treatment period, and the average value of visit 4 and visit 5 was taken to represent the value after the treatment period. Then for each subject the change was calculated by subtracting the value for before treatment from the value for after treatment. Percentual changes were calculated by calculating how large the change was compared with the value of the variable before the treatment period.

Statistical analysis of intragroup changes in the lipid and blood recordings was carried out with paired $t$-tests. Two-sample $t$-tests were used to compare the mean values of the change between the treatment groups. A well as $p$-values, the 95\% confidence intervals (CIs) corresponding to the tests were reported. Statistical computations were performed with the SAS System for Windows, release 9.1.3/2004. $p$-Values $<0.05$ were considered statistically significant. All $p$-values were twotailed.

\section{Results}

There were no differences in baseline characteristics between stanol ester and placebo groups. Serum lipid values between study groups before the treatment period were closely similar (Table 1). Other recorded blood values (blood count, s-GGT, s-ALT) were well within normal values and no differences between groups were found (data not shown).

The mean \pm SD values for the lipid measurements before and after treatment for the stanol ester and placebo groups are shown in Table 2. As shown in Fig. 1, stanol ester capsules effectively decreased total cholesterol concentrations by $4.6 \%(95 \% \mathrm{CI}$ 1.3 to $8.0 \%, p<0.01)$ and decreased LDL-cholesterol by $8.5 \%(95 \%$ CI 4.1 to $13.0 \%, p<0,001)$

Table I. Mean \pm SD values with $95 \%$ confidence intervals $(\mathrm{Cls})$ for baseline characteristics of the stanol ester and placebo groups before the treatment period

\begin{tabular}{|c|c|c|c|}
\hline \multirow[t]{2}{*}{ Variable } & \multicolumn{2}{|c|}{ Treatment group } & \multirow[t]{2}{*}{$p(95 \% \mathrm{Cl})^{\mathrm{a}}$} \\
\hline & $\begin{array}{l}\text { Stanol ester } \\
(n=22)\end{array}$ & $\begin{array}{l}\text { Placebo } \\
(n=20)\end{array}$ & \\
\hline Age (years) & $40.1 \pm 6.6$ & $40.2 \pm 5.8$ & $0.99(-3.9$ to 3.9$)$ \\
\hline Body mass index $\left(\mathrm{kg} \mathrm{m}^{-2}\right)$ & $24.8 \pm 3.0$ & $25.2 \pm 2.9$ & $0.64(-1.4$ to 2.3$)$ \\
\hline Cholesterol $\left(\mathrm{mmol} \mathrm{I}^{-1}\right)$ & $5.6 \pm 0.6$ & $5.7 \pm 0.7$ & $0.62(-0.3$ to 0.5$)$ \\
\hline $\mathrm{HDL}$ cholesterol $\left(\mathrm{mmol} \mathrm{I}^{-1}\right)$ & $1.7 \pm 0.3$ & $1.6 \pm 0.5$ & $0.27(-0.4$ to 0.1$)$ \\
\hline LDL cholesterol $\left(\mathrm{mmol}^{-1}\right)$ & $3.4 \pm 0.5$ & $3.6 \pm 0.8$ & $0.28(-0.2$ to 0.6$)$ \\
\hline Triglyceride $\left(\mathrm{mmol} \mathrm{I}^{-1}\right)$ & $1.1 \pm 0.5$ & $1.2 \pm 0.6$ & $0.58(-0.2$ to 0.4$)$ \\
\hline Lipoprotein B $\left(\mathrm{gl}^{-1}\right)$ & $1.1 \pm 0.2$ & $1.1 \pm 0.2$ & $0.30(-0.1$ to 0.2$)$ \\
\hline Lipoprotein A $\left(\mathrm{gl}^{-1}\right)$ & $1.7 \pm 0.3$ & $1.6 \pm 0.4$ & $0.37(-0.3$ to 0.1$)$ \\
\hline LDL/HDL & $2.0 \pm 0.5$ & $2.5 \pm 1.0$ & $0.05(-0.0$ to 1.0$)$ \\
\hline
\end{tabular}

HDL: high-density lipoprotein; LDL: low-density lipoprotein.

a $95 \% \mathrm{Cl}$ of the difference in the mean of the stanol ester and placebo groups. 
Table 2. Mean \pm SD values and percentual change for the lipid measurements before and after treatment for the stanol ester and placebo groups

\begin{tabular}{|c|c|c|c|c|c|c|c|}
\hline \multirow[t]{3}{*}{ Variable } & \multicolumn{6}{|c|}{ Treatment group } & \multirow{3}{*}{$\begin{array}{l}\text { Percentual change } \\
\text { in mean difference } \\
(p)\end{array}$} \\
\hline & \multicolumn{3}{|c|}{ Stanol ester $(n=22)$} & \multicolumn{3}{|c|}{ Placebo $(n=20)$} & \\
\hline & Before & After & $P(95 \% \mathrm{Cl})^{\mathrm{a}}$ & Before & After & $P(95 \% \mathrm{Cl})^{*}$ & \\
\hline Cholesterol $\left(\mathrm{mmol} \mathrm{I}^{-1}\right)$ & $5.6 \pm 0.7$ & $5.3 \pm 0.8$ & $<0.01(-0.4$ to -0.1$)$ & $5.7 \pm 0.6$ & $5.6 \pm 0.8$ & $0.29(-0.3$ to 0.1$)$ & $-3.1(0.20)$ \\
\hline HDL-cholesterol $\left(\mathrm{mmol}^{-1}\right)$ & $1.7 \pm 0.5$ & $1.8 \pm 0.4$ & $0.12(-0.0$ to 0.1$)$ & $1.6 \pm 0.3$ & $1.6 \pm 0.4$ & $0.77(-0.1$ to 0.1$)$ & $+2.1(0.53)$ \\
\hline LDL-cholesterol $\left(\mathrm{mmol}^{-1}\right)$ & $3.4 \pm 0.5$ & $3.1 \pm 0.5$ & $<0.001(-0.4$ to -0.1$)$ & $3.6 \pm 0.8$ & $3.5 \pm 0.8$ & $0.26(-0.2$ to 0.1$)$ & $-7.0(0.03)$ \\
\hline Triglyceride $\left(\mathrm{mmol} \mathrm{I}^{-1}\right)$ & $1.1 \pm 0.5$ & $\mathrm{I} . \mathrm{I} \pm 0.5$ & $0.81(-0.4$ to -0.1$)$ & $1.2 \pm 0.6$ & $1.2 \pm 0.7$ & $0.37(-0.1$ to -0.1$)$ & $+3.4(0.55)$ \\
\hline Lipoprotein B ( $\left.\mathrm{gl}^{-1}\right)$ & $1.1 \pm 0.2$ & $1.0 \pm 0.1$ & $<0.01(-0.1$ to -0.0$)$ & $\mathrm{I} .1 \pm 0.2$ & $1.1 \pm 0.2$ & $0.21(-0.1$ to 0.0$)$ & $-3.5(0.29)$ \\
\hline Lipoprotein A $\left(\mathrm{gl}^{-1}\right)$ & $1.7 \pm 0.3$ & $1.8 \pm 0.4$ & $0.03(0.0$ to 0.2$)$ & $1.6 \pm 0.4$ & $1.7 \pm 0.3$ & $0.77(-0.1$ to 0.1$)$ & $+3.6(0.30)$ \\
\hline $\mathrm{LDL} / \mathrm{HDL}$ & $2.0 \pm 0.4$ & $1.8 \pm 0.4$ & $<0.01(-0.4$ to -0.1$)$ & $2.5 \pm 1.0$ & $2.4 \pm 0.8$ & $0.09(-0.3$ to 0.0$)$ & $-7.9(0.05)$ \\
\hline
\end{tabular}

Negative values indicate decrease and positive values increase in percentual change when comparing the change in the before and after values on stanol ester treatment with the same values on placebo.

HDL: high-density lipoprotein; LDL: low-density lipoprotein.

a $95 \%$ confidence interval $(\mathrm{Cl})$ of the difference in the mean before and after stanol ester or placebo treatment.

and apolipoprotein by $6.5 \%$ (95\% CI 2.0 to $11.0 \%$, $p<0.01)$ compared with baseline. The LDL/HDL ratio was reduced by $10.6 \%$ (95\% CI 5.2 to $16.0 \%$, $p<0.001)$. HDL-cholesterol and triacylglycerol concentrations did not change significantly. In the
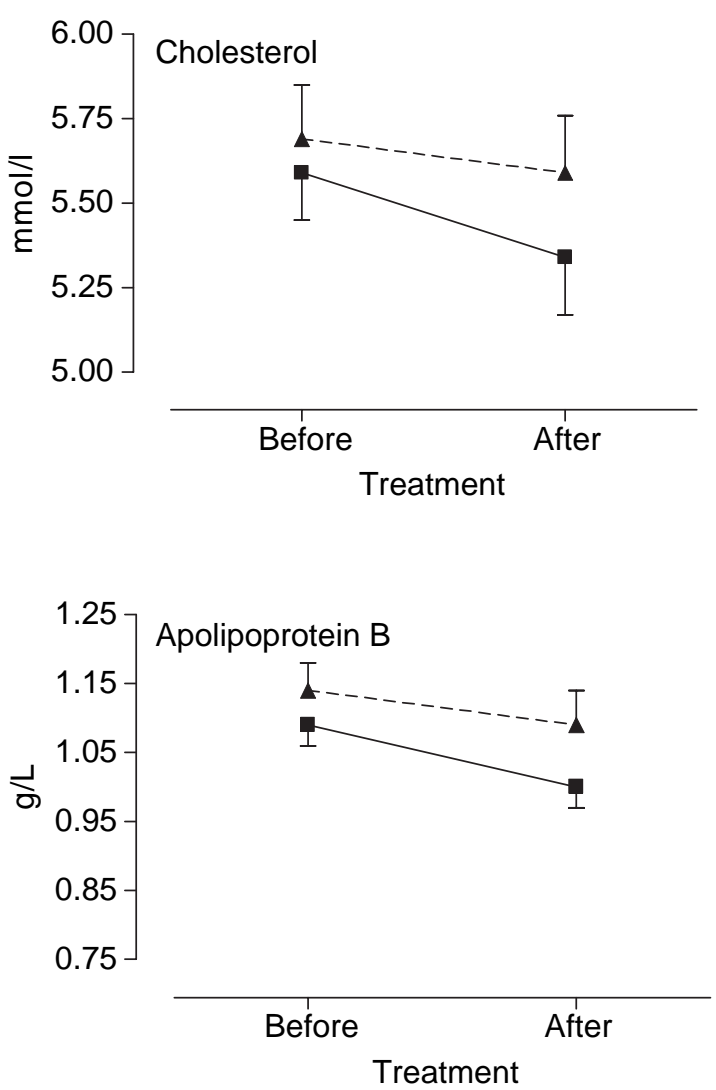

placebo group all changes in lipid values were nonsignificant.

Compared with the placebo group's results, serum LDL was significantly reduced (by approximately $7 \%, p<0.05$ ) with plant stanol capsules (Table 2).
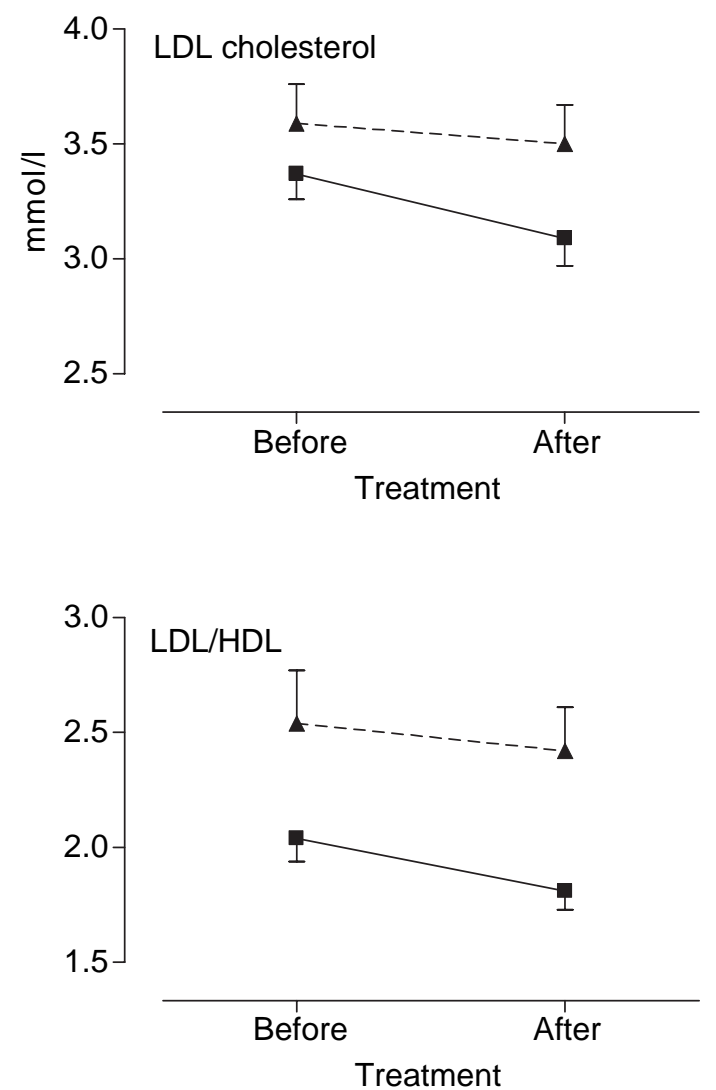

Fig. 1. Mean and SD of the changes in lipid variables before and after the treatment period for the stanol ester group (-v-) and placebo group $(-\sigma-)$. LDL: low-density lipoprotein; HDL: high-density lipoprotein. 
Subjects were following their habitual diet, and food and nutrient intake did not change during the trial (Table 3). The subjects took the capsules two or four at a time with a meal, as advised. No sideeffects were reported by subjects in health or lifestyle parameters daily during the study.

\section{Discussion}

In the present study, ingestion of plant stanol ester as capsules for 3 weeks reduced LDL-cholesterol effectively in healthy, slightly hypercholesterolaemic adults. In addition, the apolipoprotein B level was reduced from baseline during plant stanol ester use. No effects were seen in HDL-cholesterol or triglyceride levels. The cholesterol-lowering properties of plant sterols were first reported in animal experiments some 50 years ago by Peterson (1). Plant sterols and stanols reduce cholesterol absorption from the small intestine (3) and thereby serum cholesterol concentration.

Early studies with free, insoluble forms of sterols and stanols failed to show any significant efficacy, even with large doses. Denke incorporated sitostanol in capsules dispersed in oil, but failed to show cholesterol-lowering efficacy with such treatment (9). By esterification with fatty acids, stanols are rendered fat soluble and show significant cholesterol-lowering efficacy when ingested as foods (10). The first commercial food application for esterified stanol was margarine. Several clinical studies have since shown the efficacy of stanol ester in reducing serum cholesterol levels in both short- and longterm studies $(6-8,11)$. They not only play an important part in the control of cholesterol levels in healthy subjects, but also have additive effects with statins in lowering LDL-cholesterol levels in patients with coronary heart disease (CHD) (11, 12). A meta-analysis of trials conducted with plant sterols and plant stanols concluded that $2 \mathrm{~g}$ of plant stanols or sterols daily reduces the LDL-cholesterol concentration on average by $10 \%$ (5).

Early studies investigated the effect of plant stanols when ingested as several daily doses. A study on consumption frequency drew attention to the mechanism of reducing cholesterol absorption (13). It had been assumed previously that the inhibition of cholesterol absorption is based on stanol replacing cholesterol from the mixed micelles in the upper part of the small intestine. The consumption frequency study showed, however, that administering stanols once a day or three times a day was equally effective in reducing serum cholesterol level (13). This finding suggests that stanols have an additional, longer lasting effect on intestinal mucosal cells. Indeed, it has been shown that the uptake of cholesterol and other sterols into the intestinal mucosa is a rapid process and these substances are also rapidly resecreted back into the intestinal lumen (14). Recent findings suggest that apart from the micellar exclusion of cholesterol absorption there is an additional process by which stanols actively influence the cellular cholesterol metabolism within intestinal enterocytes, i.e. via activation of transporter proteins that resecrete cholesterol back to the intestinal lumen (15).

Today, there are several options for treating high cholesterol levels with pharmaceuticals. According to all international guidelines for treatment of hyperlipidaemia, emphasis should be put on diet to provide an option for individuals with lesser elevations of serum cholesterol. Restriction of saturated fatty acids and cholesterol and increasing the intake of fibre and unsaturated fatty acids reduces CHD risk. However, compliance with dietary recommendations remains a major problem. Cholesterol reductions of $15-20 \%$ have been

Table 3. Mean \pm SD values for fat, fatty acid and fibre intake before and after the treatment period for the stanol ester and placebo groups

\begin{tabular}{|c|c|c|c|c|c|c|}
\hline \multirow[t]{3}{*}{ Variable } & \multicolumn{6}{|c|}{ Treatment group } \\
\hline & \multicolumn{3}{|c|}{ Stanol ester $(n=22)$} & \multicolumn{3}{|c|}{ Placebo $(n=20)$} \\
\hline & Before & After & $P$ & Before & After & $P$ \\
\hline Fat $(E \%)$ & $36.5 \pm 10.9$ & $35.4 \pm 9.4$ & 0.51 & $34.4 \pm 7.2$ & $32.6 \pm 7.7$ & 0.21 \\
\hline Saturated fat $(E \%)$ & $13.5 \pm 4.7$ & $13.1 \pm 5.1$ & 0.57 & $13.2 \pm 3.4$ & $12.6 \pm 3.8$ & 0.24 \\
\hline Monounsaturated fat $(E \%)$ & $11.8 \pm 3.7$ & $11.1 \pm 2.8$ & 0.32 & $10.9 \pm 2.8$ & $10.4 \pm 2.9$ & 0.27 \\
\hline Polyunsaturated fat $(E \%)$ & $8.1 \pm 3.2$ & $8.0 \pm 2.9$ & 0.90 & $7.4 \pm 2.8$ & $6.7 \pm 2.7$ & 0.47 \\
\hline Fibre $(g)$ & $19.0 \pm 8.6$ & 18.49 .0 & 0.65 & $19.9 \pm 7.4$ & $21.0 \pm 7.0$ & 0.28 \\
\hline
\end{tabular}


achieved in short-term dietary trials, but long-term follow-up has mainly seen modest reductions (16, 17). Among the various food ingredients, plant stanols have proven to be the most effective components with regard to sustained and feasible cholesterol-lowering efficacy. Plant stanols are currently recommended by several authoritative bodies as part of lifestyle changes for hypercholesterolaemia management (e.g. 4).

This study shows that the food vehicle does not have to have a high content of fat to deliver the cholesterol-reducing effect. So far, the efficacy of plant sterols and stanols have been shown in highfat products such as margarines (6), high-protein products such as milk and yoghurt (18-22), and carbohydrate-rich products such as pasta, bread and cereals $(18,23,24)$. However, in a study comparing the effect in milk-based versus carbohydrate-based products, the efficacy was superior in milk products (18). The timing of the meal is also apparently of importance. It is important to note that to gain the full cholesterol-lowering effect, esterified stanol has to be hydrolysed in the upper small intestine to enter into, and replace cholesterol from, the micelles. For hydrolysis of the ester bond, pancreatic esterase is needed; this is achieved only through a stimulus by a proper amount of food entering the digestive tract. Therefore, with food vehicles that are low in fat or are only small snacks or capsules, as in this trial, it is important to consume the stanol ester product with a proper meal. In fact, a recent study showed that when a yoghurt drink with sterol ester was drunk on an empty stomach, its cholesterol-lowering efficacy was only half that when the same drink was consumed with a meal (19). In addition, one study with free and esterified sterols suggested that consumption of such a product for breakfast may not be effective (25), whereas a breakfast study with stanol ester showed a proper effect (22).

The full benefit from consuming plant stanols can be achieved when their consumption is regular and of a sufficient amount. It has been estimated that maintaining the lipid-lowering effect for a minimum of 2 years may be associated with reduced mortality from heart disease (26). Several food forms are available in which plant stanols have been incorporated to offer consumers a wide choice over several dietary patterns. Capsules with esterified plant stanols present consumers with another, easy-to-dose alternative for the incorporation of plant stanols for significant cholesterol-lowering efficacy.

\section{References}

1. Pollak OJ. Effect of plant sterols on serum lipids and atherosclerosis. Pharmacol Ther 1985; 31: 177-208.

2. Gylling H, Radhakrishnan R, Miettinen TA. Reduction of serum cholesterol in postmenopausal women with previous myocardial infarction and cholesterol malabsorption induced by dietary sitostanol ester margarine: women and dietary sitostanol. Circulation 1997; 96: 4226-31.

3. Ostlund RE Jr. Phytosterols in human nutrition. Annu Rev Nutr 2002; 22: 533-49.

4. Executive Summary of the Third Report of the National Cholesterol Education Program (NCEP) Expert Panel on Detection, Evaluation, and Treatment of High Blood Cholesterol in Adults (Adult Treatment Panel III). JAMA 2001;285:2486-97.

5. Katan MB, Grundy SM, Jones P, Law M, Miettinen T, Paoletti R, Stresa Workshop Participants, et al. Efficacy and safety of plant stanols and sterols in the management of blood cholesterol levels. Mayo Clin Proc 2003; 78: 965-78.

6. Miettinen TA, Puska $\mathrm{P}$, Gylling $\mathrm{H}$, Vanhanen $\mathrm{H}$, Vartiainen E. Reduction of serum cholesterol with sitostanol-ester margarine in a mildly hypercholesterolemic population. N Engl J Med 1995; 333: 1308-12.

7. Andersson A, Karlström B, Mohsen R, Vessby B. Cholesterol-lowering effects of a stanol ester-containing low-fat margarine used in conjunction with a strict lipidlowering diet. Eur Heart J Suppl 1999; 1: S80-90.

8. Hallikainen MA, Uusitupa MI. Effects of 2 low-fat stanol ester-containing margarines on serum cholesterol concentrations as part of a low-fat diet in hypercholesterolemic subjects. Am J Clin Nutr 1999; 69: 403-10.

9. Denke MA. Lack of efficacy of low-dose sitostanol therapy as an adjunct to a cholesterol-lowering diet in men with moderate hypercholesterolemia. Am J Clin Nutr 1995; 61: 392-6.

10. Wester I. Dose responsiveness to plant stanol esters. Eur Heart J Suppl 1999; 1: S104-8.

11. Blair SN, Capuzzi DM, Gottlieb SO, Nguyen T, Morgan $\mathrm{JM}$, Cater NB. Incremental reduction of serum total cholesterol and low-density lipoprotein cholesterol with the addition of plant stanol ester-containing spread to statin therapy. Am J Cardiol 2000; 86: 46-52.

12. Thompson GR. Additive effects of plant sterol and stanol esters to statin therapy. Am J Cardiol 2005; 96: 37-9.

13. Plat J, Mensink RP. Effects on serum lipids, lipoproteins and fat soluble antioxidant concentrations of consumption frequency of margarines and shortenings enriched with plant stanol esters. Eur J Clin Nutr 2000; 54: 671-7.

14. Igel M, Giesa U, Lutjohann D, von Bergmann $\mathrm{K}$. Comparison of the intestinal uptake of cholesterol, 
plant sterols, and stanols in mice J Lipid Res 2003; 44: 533-8.

15. Plat J, Nichols JA, Mensink RP. Plant sterols and stanols: effects on mixed micellar composition and LXR (target gene) activation. J Lipid Res 2005; 46: 2468-76.

16. Tang JL, Armitage JM, Lancaster T, Silagy CA, Fowler GH, Neil HA, et al. Systematic review of dietary intervention trials to lower blood total cholesterol in free-living subjects - Commentary: Dietary change, cholesterol reduction, and the public health - what does meta-analysis add? BMJ 1998; 316: 1213-20.

17. Jenkins DJ, Kendall CW, Faulkner DA, Nguyen T, Kemp T, Marchie A, et al. Assessment of the longerterm effects of a dietary portfolio of cholesterol-lowering foods in hypercholesterolemia. Am J Clin Nutr 2006; 83: $582-91$.

18. Clifton PM, Noakes M, Sullivan D, Erichsen N, Ross D, Annison G, et al. Cholesterol-lowering effects of plant sterol esters differ in milk, yoghurt, bread and cereal. Eur J Clin Nutr 2004; 58: 503-9.

19. Doornbos AM, Meynen EM, Duchateau GS, van der Knaap HC, Trautwein EA. Intake occasion affects the serum cholesterol lowering of a plant sterol-enriched single-dose yoghurt drink in mildly hypercholesterolaemic subjects. Eur J Clin Nutr 2006; 60: 325-33.

20. Mensink RP, Ebbing S, Lindhout M, Plat J, van Heugten MM. Effects of plant stanol esters supplied in low-fat yoghurt on serum lipids and lipoproteins, non-cholesterol sterols and fat soluble antioxidant concentrations. Atherosclerosis 2002; 160: 205-13.

21. Algorta Pineda J, Chinchetru Ranedo MJ, Guirre Anda J, Francisco T. Hypocholesteremic effectiveness of a yogurt containing plant stanol esters. Rev Clin Esp 2005; 205: $63-6$.
22. Hyun YJ, Kim OY, Kang JB, Lee JH, Jang Y, Liponkoski L, Salo P. Plant stanol esters in low-fat yogurt reduces total and low-density lipoprotein cholesterol and low-density lipoprotein oxidation in normocholesterolemic and mildly hypercholesterolemic subjects. Nutr Res 2005; 25: 743-53.

23. Salo P, Wester I. Low-fat formulations of plant stanols and sterols. Am J Cardiol 2005; 96: 51-4.

24. Quilez J, Rafecas M, Brufau G, Garcia-Lorda P, Megias I, Bullo $\mathrm{M}$, et al. Bakery products enriched with phytosterol esters, alpha-tocopherol and beta-carotene decrease plasma LDL-cholesterol and maintain plasma beta-carotene concentrations in normocholesterolemic men and women. J Nutr 2003; 133: 3103-9.

25. AbuMweis SS, Vanstone CA, Ebine N, Kassis A, Ausman LM, Jones PJ, Lichtenstein AH. Intake of a single morning dose of standard and novel plant sterol preparations for 4 weeks does not dramatically affect plasma lipid concentrations in humans. J Nutr 2006; 136: $1012-6$.

26. Law MR, Wald NJ, Thompson SG. By how much and how quickly does reduction in serum cholesterol concentration lower risk of ischaemic heart disease? BMJ 1994; 308: 367-72.

Hanna Lagström

Research Centre for Applied and Preventive Cardiovascular Medicine

Kiinamyllynkatu 10

$\mathrm{Fl}-20520$ Turku, Finland

Tel: + 35823337306

Fax: +35822331126

E-mail: hanna.lagstrom@utu.fi 